\title{
La comunidad ferroviaria de Laguna Paiva frente a las políticas desarrollistas. Argentina, $1961^{*}$
}

\author{
The Railway Community of Laguna \\ Paiva and its Response to Developmental \\ Policies. Argentina, 1961
}

\author{
Luisina Agostini $i^{* *}$ \\ (D) https://orcid.org/0000-0002-5670-0554 \\ CONICET-Investigaciones Socio-Históricas Regionales \\ Universidad Nacional de Rosario/Universidad de Buenos Aires, Argentina \\ luisinaagostini@gmail.com
}

Resumen: En este artículo explico, desde la historia local, los problemas que las políticas ferroviarias del gobierno del presidente Arturo Frondizi (19581962) generaron en la comunidad ferroviaria santafesina de Laguna Paiva (Argentina) y las maneras en que los sujetos paivenses defendieron su fuente laboral. Compruebo que las familias de Laguna Paiva construyeron y reafirmaron una identidad relacionada a los espacios ferroviarios. Sostengo que el

* Este artículo es resultado de la investigación relacionada a la tesis de maestría (Agostini, 2018a). Su escritura forma parte de las revisiones de mi investigación en el marco de la beca doctoral financiada por CONICET.

** Magíster en Ciencias Sociales mención Historia, Universidad Nacional de Quilmes. Doctoranda en Historia, Universidad de Buenos Aires. Líneas de investigación: movimiento obrero ferroviario, sociabilidades y prácticas, género y trabajo. Agradezco las sugerencias y comentarios de los revisores anónimos quienes contribuyeron a mejorar el artículo.

cómo citAr: Agostini, L. (2021). La comunidad ferroviaria de Laguna Paiva frente a las políticas desarrollistas. Argentina, 1961. Secuencia (111), e1795. DoI: https://doi.org/10.18234/secuencia.v0i111.1795

cC Esta obra está protegida bajo una Licencia Creative Commons Atribución-NoComercial 4.0 Internacional. 
contexto ideológico y político de los años sesenta se manifestó en la alta cuota de participación del actor militar en la resolución de los conflictos laborales. Demuestro el giro autoritario de las decisiones del ejecutivo nacional en el control social desplegado sobre la comunidad ferroviaria paivense. Este artículo contribuye a estudiar la conflictividad social del periodo desarrollista poco revisitada por la historiografía argentina y abona los estudios sobre los procesos de conformación de las identidades en los espacios locales.

Palabras clave: huelga; comunidad ferroviaria; historia local; políticas ferroviarias; "desarrollismo".

Abstract: In this article, I use a local history perspective to explain the problems caused by the railway policies of the government of President Arturo Frondizi (1958-1962) in the Santa Fe railway community of Laguna Paiva (Argentina) and the ways Paiva residents defended their source of employment. I prove that the families of Laguna Paiva constructed and reaffirmed an identity related to railway spaces. I argue that the ideological and political context of the 1960 s was reflected in the high participation rate of the military in the resolution of labor disputes. I prove the authoritarian nature of the national executive decisions regarding the social control of the railroad community of Paiva. This article contributes to studying the social conflict of the Developmentalist period that has scarcely been studied by Argentine historiography and explores the processes of shaping identities in local spaces.

Keywords: strike; railway community; local history; railway policies; "developmentalism"

Recibido: 14 de octubre de 2019 Aceptado: 8 de junio de 2020

Publicado: 30 de julio de 2021

\section{INTRODUCCIÓN}

n 1961, el movimiento obrero argentino protagonizó una huelga nacional 
nantes y analizamos el impacto local que tuvieron las políticas ferroviarias nacionales que se implementaron como parte del proyecto desarrollista diseñado por el gobierno de Arturo Frondizi (1958-1962) en la comunidad santafesina de Laguna Paiva. Los embates de estas medidas sobre el mundo del trabajo ferroviario constituyeron un escenario conflictivo que estudiamos a partir de las acciones y discursos del gobierno nacional y de las organizaciones gremiales ferroviarias durante la huelga. Trabajamos con fuentes gremiales de las centrales de La Fraternidad y la Unión Ferroviaria, de la seccional paivense y con material de la prensa nacional y local. Analizamos las respuestas que los habitantes de Laguna Paiva elaboraron para sostener la huelga nacional ferroviaria. Contamos con entrevistas realizadas a trabajadores ferroviarios y sus familias que vivieron en la localidad durante el paro ferroviario; sus memorias son importantes para explicar la dinámica social y los efectos que los procesos y problemas locales han tenido en la constitución y reconstitución de las identidades individuales y colectivas que le dan sentido a la historia. ${ }^{1}$

Cuando en 1958 Arturo Frondizi asumió la presidencia de la República Argentina y como parte de la preocupación por disminuir el déficit que las empresas públicas generaban en la economía es que emprendió una política de racionalización sobre el sistema ferroviario. El proyecto que el gobierno nacional diseñó para llevar a cabo la "batalla del transporte"2 en 1961 significó el cierre de ramales y talleres, la reducción de personal, la jubilación anticipada de trabajadores. Estas disposiciones fueron de alcance nacional, pero impactaron negativamente sobre las estructuras sociales y laborales de diferentes localidades del interior del país, que vivían en torno al trabajo ferroviario, como fue el caso de Laguna Paiva, en la ciudad argentina de la provincia de Santa Fe. Allí, el trabajo ferroviario en los talleres de reparación de vagones era el sustento económico, social y cultural de la comunidad desde principios del siglo xx.

La respuesta colectiva de los trabajadores fue la huelga nacional ferroviaria que se inició el 30 de octubre de 1961. Los gremios de La Fraternidad y la Unión Ferroviaria centralizaron las negociaciones y las formas de lucha. Pero, durante los 42 días de paro existieron formas autónomas de acción colectiva

\footnotetext{
${ }^{1}$ Los fragmentos de las entrevistas que compartimos aquí fueron realizados por la autora a varones y mujeres de Laguna Paiva entre 2015 y 2017.

2 Arturo Frondizi, "La batalla del transporte", discurso pronunciado por radio y televisión desde el Salón Blanco de la Casa de Gobierno, el 5 de junio de 1961. En Mensajes presidenciales 1958-1962, t. III. Fundación Centro de Estudios Presidente Arturo Frondizi. Recuperado de https://www.fundacionfrondizi.org.ar/
} 
que incluyeron a las familias de los ferroviarios en comunidades que debían su desarrollo económico y social a la única fuente laboral, los talleres ferroviarios. ${ }^{3}$ Sostenemos que las medidas del desarrollismo sobre el transporte ferroviario generaron, en escenarios locales, alejados de la geografía porteña y desplazados por el nuevo proyecto, una ruptura económica y social que se profundizó décadas siguientes dando lugar a comunidades ferroviarias desestructuradas y a pueblos "fantasmas" sin ferrocarril. ${ }^{4}$ También, consideramos que el contexto ideológico y político de los años sesenta se manifestó en la alta cuota de participación del actor militar en la resolución de los conflictos laborales que, a tono con la preocupación por el "enemigo subversivo", diseñó una fuerte estrategia de disciplinamiento social aprobada por el ejecutivo nacional.

Por las fuentes con las que contamos y por los horizontes de esta investigación, este trabajo contribuye al campo historiográfico analizando el impacto de las medidas económicas y político-militares en la localidad santafesina de Laguna Paiva durante el paro ferroviario. Estudiamos la localidad paivense como un espacio construido y habitado por sujetos con una identidad relacionada con los lugares donde vivieron, trabajaron y lucharon. Adherimos a la historia local ${ }^{5}$ como metodología que posibilita hacer más denso el estudio de los procesos sociales, no porque lo local sea ejemplo de los cambios nacionales sino porque lo local expresa la singularidad en que esos cambios (en este caso, el intento de racionalización ferroviaria) se relacionan con la trama social que sostiene la vida de las personas.

${ }^{3}$ Entre las investigaciones que específicamente abordaron el ámbito ferroviario durante el desarrollismo se encuentran los estudios de Mengascini (2011), el autor analiza el impacto que el desguace del ferrocarril generó en los trabajadores agrupados en los sindicatos del riel de la localidad de Tandil. Interesa este estudio para recuperar el enfoque que desde las estructuras sindicales se conforma sobre el proceso de organización y acción del movimiento obrero ferroviario de Tandil. La huelga ferroviaria de 1961 en Mendoza es analizada por Scodeller (2007), la autora realiza una descripción de los hechos y considera que fue muy importante la solidaridad entre los obreros del riel para sostener las medidas de fuerza.

${ }^{4}$ Más adelante profundizaremos sobre esta cuestión trabajada por Müller (2007) y discutida por Damín y Aldao (2015).

${ }^{5}$ En la historiografía Argentina de los últimos 30 años han crecido las investigaciones y los estudios regionales y locales, existe una producción aún dispersa y ligada a los trabajos emanados desde unidades, centros y proyectos que ubican a la dimensión regional y local como uno de sus objetivos de estudio. Estas cuestiones a las que adherimos se desarrollan en Fernández (2007; 2015), también aquellos aportes compilados en Bandieri y Fernández (2017) que han trabajado sobre las redefiniciones de lo regional y lo local privilegiando los espacios humanos y las relaciones sociales como elementos dinámicos y constitutivos para leer los procesos históricos afincados a determinados recortes espaciales. 
A continuación, en el primer apartado, realizamos un repaso historiográfico por las políticas ferroviarias argentinas con relación a las transformaciones económicas mundiales. Consideramos que la problemática ferroviaria argentina se relaciona con la crisis mundial del modo ferroviario desde los años treinta y esto es importante para explicar, luego, las políticas desarrollistas que nos interesan en este artículo. En el segundo apartado recuperamos los balances que los investigadores han construido sobre las dificultades económicas de la EFEA (Empresa de Ferrocarriles del Estado Argentino, posteriormente llamada Ferrocarriles Argentinos), que estaba en manos del Estado nacional cuando se llevó a cabo el conflicto ferroviario de 1961.

En tercer lugar, explicamos las características del trabajo ferroviario en los talleres paivenses para dar cuenta de la importancia del nudo socioeconómico, laboral e identitario eje del funcionamiento de la comunidad santafesina y escenario de la lucha social. En cuarto lugar, analizamos discursos gubernamentales y gremiales emitidos durante los 42 días de huelga, los que refieren a las formas de organización del movimiento obrero ferroviario como a las medidas de control social sostenidas por el gobierno frondicista para cumplir sus objetivos. En quinto lugar, explicamos las formas en que esos discursos y acciones impactaron en Laguna Paiva. A propósito, nos interesan dos cuestiones: la manera en que una comunidad ferroviaria trascendió a los trabajadores y defendió su fuente laboral y las características que adquirió la materialización de la violencia sobre el pueblo ferroviario por parte de las fuerzas de seguridad. Por último, formulamos conclusiones sobre la importancia de un enfoque desde la historia local para poder dimensionar las tensiones entre procesos nacionales que se piensan y escriben desde los centros de poder y las experiencias de vida de los sujetos (en este caso ferroviarios) en pos de resolver los problemas localmente situados.

\section{LAS POLÍTICAS FERROVIARIAS ARGENTINAS Y LA CRISIS DEL FERROCARRIL}

El sistema ferroviario argentino se constituyó en eje del modelo agroexportador a fines del siglo xIX. La organización de este transporte por el Estado liberal conservador y administrado por empresas extranjeras y el Estado tuvo su esplendor en las primeras décadas del siglo xx. Las políticas nacionalizadoras de los años cuarenta se ocuparon de un sistema ferroviario ya técnicamen- 
te debilitado, con una escasa inversión y modernización detenida desde los años treinta. El modelo de desarrollo peronista a nivel industrial no revirtió esta situación como tampoco las políticas que en materia ferroviaria se implementaron luego de 1955. El ferrocarril, en Argentina, no fue el medio de transporte privilegiado del siglo $\mathrm{xx}$, y esto se evidenció en la batería de disposiciones que, lejos de recuperar y modernizar el sistema, lo desestructuraron $y$ destruyeron.

A diferencia del proceso europeo de establecimiento ferroviario, donde las vías unieron ciudades y pueblos; en Argentina, su trazado creó y configuró espacios sociales y económicos. Jorge Schvarzer (1999) postula que, en la Argentina agroexportadora del siglo xIx, los rieles se ligaron a la sociedad y la economía local y la administración extranjera de los ferrocarriles presentó dificultades económicas y de infraestructura como consecuencia del fuerte impacto de la crisis económica de 1929-1930. Los años treinta significaron, además, la intervención estatal y la creación de instituciones del transporte como la Dirección Nacional de Vialidad (1932) que construyó caminos paralelos a las vías férreas. La radicación de empresas norteamericanas subsidiarias de Ford Motors (1917), General Motors (1925), Good Year (1930) y Firestone (1931) daban cuenta del desarrollo del mercado de consumo de automóviles.

Para el historiador Jorge Waddel (2007), en la década de 1930 las empresas extranjeras a cargo del sistema ferroviario realizaron las últimas políticas empresariales de racionalización, de reformulación de los servicios (por ejemplo, la incorporación de trenes diurnos) como también algunas inversiones para competir con el incipiente transporte automotor. Pero, el impacto de la crisis económica mundial evidenció que el modo ferroviario que en Europa y Estados Unidos ya presentaba problemas frente al crecimiento del transporte automotor, en Argentina agudizó la importancia de una red vial que comenzaba a crecer frente a un retraimiento de las cargas transportadas por el ferrocarril (López, 2007). Esta situación afectó tanto a las empresas extranjeras como a la estatal a cargo del sistema ferroviario. Para Salerno (2007) desde fines del siglo xix y las primeras décadas del siglo xx los ferrocarriles estatales adolecieron de una insuficiencia crónica de recursos financieros que afectó su funcionamiento. ${ }^{6}$

${ }^{6}$ Esto es importante de tener en cuenta porque los talleres de Laguna Paiva fueron estatales hasta su privatización de la década de 1990. 
Mientras que durante la nacionalización del sistema en los años peronistas no existió una renovación de vías, ni trenes, el tráfico ferroviario de cargas disminuyó y, junto con ello también la productividad, pero no así fue el caso del personal (Belini y Korol, 2012, p. 130). Aquel proceso nacionalizador formó parte de las políticas de intervención estatal y ampliación de los derechos sociales de los trabajadores (Sidicaro, 2002; Torre, 2001). Pero la elaboración de una política austera a partir de 1952 implicó un plan de ajuste, afectando los salarios, reduciendo el gasto público, flexibilizando la entrada de capitales extranjeros contradiciendo, así, la política de independencia económica sostenida años atrás. En el caso de los ferroviarios, se agudizó la tensión entre la dirigencia sindical y las bases trabajadoras, no todas peronistas. Es en este marco que se desarrollaron una serie de conflictos obreros y adquirieron relevancia las huelgas ferroviarias de 1950 y 1951.

Entre la nacionalización ferroviaria y los primeros años de la década de los sesenta se llevaron a cabo medidas de corto plazo con el propósito de intentar reducir el déficit; por ejemplo, se renovó gran parte de las locomotoras que pasaron de su funcionamiento por vapor a la tracción diesel. Pero, el nuevo material rodante tenía que transitar por vías que no estaban preparadas (Mengascini, 2011). Para los golpistas de 1955, los debates sobre los problemas heredados del gobierno anterior y sobre los rumbos a seguir por la economía posperonista daban cuenta de la ausencia de una postura clara y consensuada entre quienes lideraron el país hasta 1958. Coincidieron en favorecer la integración de Argentina a los organismos internacionales creados luego de la segunda guerra mundial, como el Fondo Monetario Internacional y el Banco Mundial como parte de los consejos de Presbich para fomentar las inversiones extranjeras y alentar el comercio exterior (Belini y Korol, 2012).

\section{DE CÓMO LAS POLÍTICAS FERROVIARIAS FUERON CONSIDERADAS UNA "BATALLA CONTRA EL RIEL"}

Cuando Arturo Frondizi, candidato de la Unión Cívica Radical Intransigente, ganó las elecciones en 1958, la realidad económica del posperonismo, el escenario político militar, las presiones sociales y sus decisiones endurecieron los alcances del desarrollismo. Entonces, las inversiones extranjeras (Ley 14780) fueron orientadas para promover un desarrollo de los niveles del esquema industrial: industria liviana, industria pesada y tecnificación agrícola, así 
como también la consolidación de núcleos fabriles en el interior del país. En este periodo aumentó la estructura productiva ligada a la industria automotriz, que contó con neumáticos, combustibles, motores, entre otros. También, el transporte de carga y de pasajeros contó con subsidios y nuevos caminos construidos por Vialidad Nacional, superpuestos al trazado ferroviario (Katz y Kosacoff, 1989; Vaccarezza, 2010; Vicentin, 2013).

Mengascini (2011) plantea que el crecimiento de la industria automotriz, por un lado, y el plan extranjero de reestructuración de los ferrocarriles, Plan Larkin, por otro, constituyeron el contexto fundamental para el paro ferroviario de 1961. El plan que fue encargado al militar estadunidense Thomas Larkin, especialista en temas de transporte y presentado recién en 1962; los trabajos para elaborar el informe final fueron realizados durante 1961. No obstante, se lo consideró causante del paro obrero que estudiamos, pese a que muchas de esas medidas no eran recomendadas por el informe final del plan Larkin. El investigador Ortega (2010) advierte que ese plan destacaba el pésimo estado de la infraestructura ferroviaria, indicaba eliminar material obsoleto, modernizar la red con la compra de locomotoras diesel, reducir personal (principalmente en administración y gerencia) pero no planteaba abandonar el sistema ferroviario.

En mayo de 1961, el Decreto Nacional Núm. 4061 ordenó el levantamiento de $2300 \mathrm{~km}$ de vías férreas, la clausura de numerosos talleres y la cesantía y jubilación anticipada de casi 10000 trabajadores. Declaró congelado el déficit de explotación de los ferrocarriles nacionales y estableció la necesidad de suprimir aquellos servicios que fueran "antieconómicos" en pos de racionalizar el trabajo del personal para lograr una eficiente productividad. Además, estableció la privatización de las prestaciones complementarias de la actividad ferroviaria como, por ejemplo, restaurantes, coches comedores y confiterías. Antonio Di Santo (1999) escribe que estas cuestiones formaban parte de los artículos 5 y 49 del decreto, como también que esta norma concedía facultades extraordinarias al ministro de Obras y Servicios Públicos, Arturo Acevedo. Para el sindicalismo ferroviario, desde mayo de 1961 el gobierno había emprendido una "Batalla contra el riel" que no sólo atacaba a las estructuras materiales ferroviarias sino a la idoneidad y moralidad de los trabajadores que defendían su trabajo cualificado y "enfrenta[ban] una campaña de desprestigio desatada desde las esferas oficiales. [...] con el levantamiento de líneas, la entrega de las confiterías, la entrega de los servicios auxiliares [...] 
la entrega de los talleres montados con capital nacional a industriales aprovechados. Recién después sobrarán obreros".

La aplicación de estas medidas sobre el transporte ferroviario impactó directamente en los lugares de trabajo de los ferroviarios, en la estructura de la EFEA y tensionó las relaciones entre el gobierno y las centrales sindicales.

\section{EL TRABAJO FERROVIARIO EN LOS TALLERES PAIVENSES}

El tendido del ramal San Cristóbal-Santa Fe correspondiente al Ferrocarril Central Norte dejó como resultado la habilitación de la estación Laguna Paiva en 1908. La localidad paivense fue el asiento del personal de dirección y trabajo de construcción del ramal Laguna Paiva-Deán Funes a partir de lo que comenzaron las obras para crear el depósito de locomotoras inaugurado en 1913. Esto produjo la instalación de otras instituciones que acompañaron el crecimiento poblacional de la localidad fundándose en ese año el pueblo Reynaldo Cullen, que debido a la impronta del nombre de su estación ferroviaria se denomina popularmente Laguna Paiva.

El ferrocarril ejerció una fuerte influencia en el trazado urbano, ya que los primeros espacios que se fueron loteando se ubicaban en las proximidades de la estación de trenes, del depósito de locomotoras y a lo largo de las vías de los ramales Deán Funes y San Cristóbal. Fueron necesarios locales comerciales para proveer artículos de consumo a los obreros de las cuadrillas de trabajo como también instituciones públicas que se fueron creando en los primeros años de la década de 1910 (Paúl, 2015). Los talleres ferroviarios se posicionaron como dinamizadores económicos y sociales del pueblo. La tecnología aplicada a los mismos, el número de obreros empleados en las instalaciones, las secciones y especializaciones de cada unidad de producción y trabajo fue cambiando a lo largo del siglo xx. En 1945 el taller contaba de 30000 metros cuadrados y "edificio de administración, usina, taller eléctrico, aserradero, carpintería de vagones, remachadores, levante de vagones y reparación, frenos, herrería, herrería mecánica, tornería de ruedas, tornería mecánica,

7 “La 'Batalla contra el riel', solicitada de la Unión Ferroviaria y La Fraternidad”, La Razón, 29 de mayo de 1961. 
broncería y hojalatería, caldería pesada y caldería de chapas, herramentaje, pinturería, instalaciones y playa". 8

El auge ferroviario permitió el crecimiento de la mano de obra y muchas personas de diferentes puntos del país llegaban para trabajar superando la capacidad habitacional del pueblo. Esta situación generó la conformación de los barrios Villa Obrera y Villa Talleres.

Entre las décadas de 1930 y 1960, Laguna Paiva asistió a un desarrollo laboral, urbano y cultural que le permitirá en 1967 ser declarada ciudad. Según los datos del censo de 1960, la población total del pueblo Reynaldo Cullen era de 11881 habitantes, diferenciándose 5914 varones y 5967 mujeres. ${ }^{9}$ Los talleres, durante la nacionalización peronista, formaron parte del Ferrocarril General Belgrano.

Desde 1958, trabajaron en el taller 1740 agentes, sin contar los trabajadores de otros sectores ferroviarios como personal de conducción, señaleros, personal de vía y obra, personal de la estación, comedor, cocina, entre otros. ${ }^{10}$ En Laguna Paiva el trabajo ferroviario no sólo tenía la función productiva y salarial, sino que permitió la construcción de vínculos más personales a los que se darían si se tratara de otro tipo de actividad de tipo industrial más compleja y en una geografía urbana más desarrollada. Como consecuencia de la huelga de 1961, los sucesivos censos poblacionales van a registrar disminución de la población, resultado de la crisis del sistema ferroviario que va a producir expulsión de sus habitantes más jóvenes hacia la ciudad capital de Santa Fe en búsqueda de trabajo (Paúl, 2015). ${ }^{11}$ Este proceso tuvo su golpe fatal en la década de 1990 con la privatización y cierre de los talleres paivenses (Agostini y Brandolini, 2016). Consideramos que la comunidad ferroviaria de Laguna Paiva vivió un proceso de desestructuración de los espacios ferro-

${ }^{8}$ El Litoral, 26 de marzo de 1945, p. 3.

${ }^{9}$ Censo Nacional de Población 1960, tomo Iv. Zona Central. Santa Fe-Córdoba: Dirección Nacional de Estadísticas y Censos. Recuperado de http://www.santafe.gov.ar/archivos/estadisticas/censos/Censo1960.pdf p. 262.

${ }_{10}$ Información publicada en Revista Identidad, año 2, núm. 2, abril, 1993. Biblioteca Alberdi, Laguna Paiva.

${ }_{11}$ Nuestros entrevistados paivenses se han referido a la localidad actual como una "ciudad dormitorio", esto supone que no hay ofertas laborales que permitan el crecimiento demográfico porque se asiste a una alta población anciana y poca población joven y en edad activa. Laguna Paiva al estar a pocos kilómetros de la ciudad capital de Santa Fe se convirtió en una localidad dormitorio porque sus habitantes viven en Paiva pero estudian y trabajan en Santa Fe, solo vuelven a dormir a sus hogares. 
viario, social, identitario y económico a partir de las políticas de 1961. Esto es importante porque acordamos con la expresión pueblos "fantasmas"12 para nuestro caso de estudio; creemos que el cierre de la fuente laboral como resultado de los proyectos políticos antiferroviarios entre las décadas de 1970 y 1990 implicó no sólo un proceso traumático en la vida de los trabajadores ferroviarios y sus familias y adherimos a lo señalado en Damín y Aldao (2015) que "Es verdad que no desaparecieron todas. Pero sufrieron transformaciones vitales para comprender las experiencias, posibilidades y futuros de comunidades que eran atravesadas por el transporte de pasajeros, y, sobre todo, aquellas donde funcionaban centros neurálgicos de la vida ferroviaria, sean talleres, estaciones, tornavías, señalizaciones” (p. 139).

\section{TRABAJADORES EN HUELGA, RIELES VIGILADOS Y DISCURSOS ENFRENTADOS}

Cuando recorrimos los registros de la prensa desde mayo a octubre de 1961, detectamos que la huelga de 42 días fue el resultado de un duro enfrentamiento entre las autoridades del gobierno y los gremios en pos de definir los alcances del déficit del sistema ferroviario y el tipo de progreso económico pretendido para la nación. Los dos actores coincidían en que era necesario redefinir la estructura ferroviaria, pero exponían discursos y prácticas diferentes. La EFEA fue creada en 1956 con el propósito de unificar el control y funcionamiento de las líneas férreas y poder realizar una serie de modificaciones, de acuerdo con un proyecto económico diferente al peronista que, durante el periodo del gobierno de Arturo Frondizi, tendrá vaivenes políticos, cambios de funcionarios y directivas. A partir de mayo de 1961, el nuevo equipo técnico liderado por Arturo Acevedo, ministro de Obras y Servicios Públicos, endureció los objetivos a seguir (López y Waddel, 2007).

La huelga ferroviaria de 1961 se llevó a cabo en todo el país; para Jorge Larroca y Armando Vidal (1987) fue en defensa de los ferrocarriles y no consistió en un reclamo salarial. Ellos plantean que puede leerse dentro del reper-

${ }^{12}$ Teniendo en cuenta el planteo de Müller (2007) no consideramos que para nuestro caso de estudio la denominación de pueblo fantasma relacionado con la ausencia del ferrocarril se trate de un mito o una expresión romántica, sino que supone un complejo proceso de destrucción social, económica e identitaria de una comunidad. 
torio de lucha del movimiento obrero ferroviario como un mojón diferente. Lejos de conseguir quebrar la lógica económica de las políticas del gobierno frondicista, pero con la intención manifiesta de cuestionarlo y enfrentarlo, el movimiento ferroviario en 1961 recuperó tradiciones anteriores de lucha, las acciones colectivas aprendidas históricamente, pero condensadas en un nuevo escenario político y militar.

Las intenciones puestas en las negociaciones que la cúpula sindical tenía con el gobierno en pos de integrar el directorio de la EFEA, conservar las posiciones que se lograron cuando se regularizó el funcionamiento sindical luego de las intervenciones sufridas antes del triunfo electoral de Frondizi, no eran las mismas preocupaciones de los trabajadores de base, quienes tenían que lidiar con la falta de trabajo, el aumento de precios, la caída de los salarios. Belini y Korol (2012) plantean que la colaboración y apoyo de los sindicatos peronistas durante los primeros años del gobierno frondicista cambió a partir del impacto negativo de las políticas económicas en los salarios reales de los trabajadores, que desde 1958 se acompañó de la retracción del crédito, devaluación y aumento de tarifas de servicios públicos. Esta situación se agudizó cuando el gobierno aplicó el Plan Conintes (Conmoción Interna del Estado), para reprimir las huelgas y protestas del periodo. Por ejemplo, en 1958 el ejecutivo ordenó estado de sitio y dispuso la movilización militar de los trabajadores del riel que estaban realizando protestas por el cobro atrasado de sus haberes.

En 1961, el gobierno expuso un diagnóstico negativo de la situación económica del país una vez iniciada la huelga ferroviaria, aseguraba que el paro no hacía más que aumentar el déficit económico ya existente y que impactaba sobre toda la población. Según el comunicado que el Ministerio de Obras y Servicios Públicos de la Nación dio a conocer el 30 de octubre de 1961, cuando se inició el paro, se estableció que la acción del movimiento ferroviario era llevada a cabo por una dirigencia gremial que atentaba contra la "comunidad nacional". No proponía ninguna solución concreta a "un sistema ferroviario anacrónico y en situación de quebranto" sino que impedía las negociaciones pacíficas entre las partes mediante sus acciones violentas, $y$ atentaba contra la economía nacional al perjudicar sus ingresos y ocasionar problemas en las actividades cotidianas de los usuarios. ${ }^{13}$ El presidente remarcaba que a la mala situación estructural del transporte se sumaba "la grave situación financiera

${ }^{13}$ El Litoral, 30 de octubre de 1961. 
determinada por el déficit del orden de los 23000 millones de pesos anuales". ${ }^{14}$ Con respecto al derecho a huelga, en un contexto político inestable y con la creciente cuota de intervención de las fuerzas armadas y de las fuerzas policiales a la hora de reprimir a los trabajadores, Frondizi sostenía que frente al paro general que acompañaba a la lucha ferroviaria del 5 de octubre de 1961:

[...] el respeto de los poderes públicos por el derecho de huelga no debe ser confundido con la tolerancia frente al abuso de esa medida [...] si el abuso del derecho a huelga, que no es el único derecho, sino uno de los instrumentos de lucha de los trabajadores por su significación económica y social ha jalonado de derrotas gremiales estos tres últimos años, la razón de esas derrotas está, precisamente en ese mismo abuso. ${ }^{15}$

Estas ideas se relacionaban con el despliegue de acciones violentas, a medida que el paro se prolongaba en el tiempo. Cuando se inició la huelga ferroviaria de 1961 se fortalecieron formas de control social y se autorizó a la Gendarmería Nacional, la Policía Federal y la Prefectura Nacional Marítima para llevar a cabo la "vigilancia, de desplegar medidas preventivas y servicios de patrullaje". ${ }^{16}$ También, el ejecutivo nacional dispuso requisa sobre los ferroviarios que no se presentaran a trabajar y esta alcanzó a sus identificaciones políticas; de esta forma, la persecución a los trabajadores comunistas formó parte de este proceso de vigilancia en clave antisubversiva. Los ferroviarios detenidos que estaban a disposición del poder ejecutivo no tenían un proceso judicial o acusación delictiva alguna, por lo que en los boletines de huelga y en las circulares generales se brindaba información periódica sobre las situaciones de estos trabajadores y las indicaciones a seguir frente a posibles detenciones. Por ejemplo, como los abogados gremiales no podían solicitar el habeas corpus de los prisioneros, porque la justicia ordinaria estaba limitada o era inexistente en estos casos, "la labor de los abogados se limita entonces a verificar las condiciones de encarcelamiento o detención, para lo cual hemos dispuesto la visita periódica a los establecimientos donde han sido remitidos". ${ }^{17}$

${ }^{14}$ El Litoral, 6 de noviembre de 1961.

${ }_{15}$ La Capital, 5 de octubre de 1961.

${ }^{16}$ Denominaciones explicitadas por las autoridades nacionales al ofrecer a la prensa las disposiciones oficiales a seguir ante el conflicto.

${ }_{17}^{17}$ La Fraternidad, Circular General, 23 de noviembre de 1961. 
Beatriz Filiberti (2010) plantea que el tema del desarrollo en la agenda política de Frondizi dominó y subordinó al resto de los problemas. La investigadora sostiene que la propuesta de desarrollo en democracia se revirtió cuando la condición para lograrlo pasaba a ser la seguridad. Entonces, el gobierno nacional intentó, pero sin éxito, articular demandas sindicales con nuevas líneas económicas basadas en tecnificación, racionalización y capitales extranjeros. ${ }^{18}$

Para los gremios, dentro la definición de las nuevas formas que adquiriría el sistema ferroviario, las experiencias laborales no se estaban teniendo en cuenta y a ellos les interesaba asegurar el lugar de la clase obrera dentro de la EFEA, de manera que los trabajadores no perdieran sus conquistas laborales. También planteaban el desconocimiento que el equipo económico y técnico del gobierno tenía respecto al trabajo ferroviario y a las necesidades concretas para el buen funcionamiento del sistema. De esta manera, el discurso gremial sostenía que el móvil de estas decisiones irracionales estaba dado por "los extremismos políticos y las fuerzas empresarias representadas por grandes grupos de ingeniería, trusts industriales, empresas camineras, consultores económicos y técnicos [...] que pretenden aprovechar el esfuerzo nacional", ${ }^{19}$ construyendo también una imagen negativa del obrero ferroviario en la opinión pública, abonando la figura de trabajadores vagos, irresponsables, que sólo intentaban conseguir logros a costa de un paro que afectaba a toda la población, con posturas antidialoguistas. La pretendida integración en comisiones estatales-gremiales se cortó cuando se impuso el proyecto de reestructuración sin previa discusión con los representantes de las organizaciones obreras. También, sostenían que la organización gremial perdería poder y fuerza, al ser absorbida por una lógica diferente en la articulación del capital y el trabajo que no tendría en cuenta las reivindicaciones obreras. ${ }^{20}$

Para coartar la medida de fuerza, el gobierno aplicó un plan requisitorio que se complementó con el llamado a los aficionados y jubilados ferroviarios para conducir locomotoras y, así, garantizar el servicio de transporte a la sociedad argentina. Aquellos "que patrióticamente y voluntariamente se ofrezcan a hacerlo, y toda persona idónea que acuda al mismo afecto ante las

\footnotetext{
${ }_{18} \mathrm{Al}$ respecto tenemos presente los siguientes aportes bibliográficos, Jorge Schvarzer (2000); Martín Unzué (2012); Pablo Gerchunoff y Lucas Llach (2005).

${ }^{19}$ La Razón, 29 de mayo de 1961.

${ }^{20}$ La Fraternidad, seccional Laguna Paiva, Boletín de Huelga, núm. 5, 1961, sin fecha exacta.
} 
autoridades", ${ }^{21}$ recibirían altos salarios. Como también, quienes no acompañen el objetivo del movimiento ferroviario y muestren la bandera nacional en aquellos vagones que iban a circular quebrando la medida de fuerza. A partir de estas acciones, los documentos gremiales dedicaron parte de su contenido a advertir a la población sobre los peligros que ocasionaba la conducción de las máquinas por inexpertos y, sobre el perjuicio moral que significó, para los fraternales, desafiar su profesionalismo intrínseco que los diferenciaba de los demás grupos de ferroviarios. Así, por ejemplo: "La Fraternidad quiere advertir a la población sobre el riesgo de viajar en trenes que eventualmente conducirán improvisados hombres, sin experiencia alguna [...] que conspira contra la vida y seguridad de los viajeros." ${ }^{22}$

No todos los trabajadores sostuvieron el paro. Durante los días de huelga el sindicalismo ferroviario estaba preocupado por aquellos obreros que aceptaban las indemnizaciones propuestas por el gobierno y abandonaban sus empleos y la lucha. Entre las opciones concretas que los trabajadores encontraron frente a la compleja situación laboral, trabajar y convertirse en "krumiro" o aceptar la indemnización también constituyeron las decisiones que muchos ferroviarios tomaron. Existieron, entonces, conflictos internos entre los trabajadores que componían la planta de la EFEA, que abarcaba diferentes oficios, profesiones y niveles de jerarquía. El discurso fraternal se preguntaba también, si quienes integraban la clase obrera ferroviaria eran verdaderamente los que se identifican con la causa de lucha. Estas cuestiones se anclaban en las experiencias laborales situadas entre aquellos oficios que suponían el trabajo más duro en las vías y talleres, como aquellos que implicaban un conocimiento técnico específico para el manejo de las locomotoras. Las situaciones anteriores permiten matizar entonces los alcances del acatamiento del paro y también del escenario sindical verticalista y homogéneo que unificaba las acciones a seguir durante la huelga. No obstante, las fuentes gremiales eran bien contundentes con la organización del movimiento y lo que se esperaba de cada trabajador.

A partir del 1 de noviembre, la preocupación central del movimiento fue buscar estrategias que posibilitaran obstaculizar y hacer fracasar el plan de requisa del gobierno; es por esto que en los documentos gremiales se explicitaban indicaciones a seguir frente a los allanamientos, intimidaciones,

${ }^{21}$ El Litoral, 6 de noviembre de 1961.

${ }^{22}$ La Fraternidad, Comunicado de Prensa, 3 de noviembre de 1961. 
persecuciones y demás acciones realizadas hacia la organización gremial, los obreros y sus familias, tendentes a quebrar la medida. Asambleas de trabajadores, manifestaciones públicas y divulgación propagandística integraron el repertorio de acción constante del movimiento ferroviario nacional. También, las donaciones económicas en dinero y productos de consumo básico de afiliados y otras instituciones colaboraron materialmente con el "fondo de huelga" que fue el sostén económico de la acción cuando, el 15 de noviembre, la Comisión Directiva de La Fraternidad indicaba utilizarlos porque "las empresas ferroviarias interrumpieron los giros de la cuota sindical a las entidades gremiales". ${ }^{23}$

Los medios de comunicación se hicieron eco de algunos ejes centrales del discurso del gobierno y los explicitaban a la opinión pública, colaborando en conformar un esquema de pensamiento de gran parte de la sociedad favorable a las medidas de las autoridades. El diario La Capital, de la ciudad de Rosario, publicó un editorial, con fecha del 30 de octubre de 1961, titulado "Llamamiento a la concordia". El texto reprodujo fragmentos del mensaje que Frondizi expresó en actos oficiales en Rafaela y Corrientes, en los que se refirió al problema ferroviario. El diario estaba de acuerdo con el ejecutivo nacional en que los trabajadores debían reflexionar sobre la medida de paro, que afectaba a la ciudadanía entera, porque frenaba las actividades cotidianas del comercio, de la industria y no aportaba soluciones a la crisis del sistema ferroviario tal como se encontraba. El editorial decía: “¿Pueden esos obreros, legítimamente, pedir que continúe un estado de cosas que significa el mantenimiento del déficit de 23.000 millones de pesos al año, que soporta toda la colectividad?" y, agregaba que "corresponde que los trabajadores ferroviarios revean las actitudes inconsultas que han adoptado, comprendan las razones que justifican los cambios decididos por el gobierno". ${ }^{24}$

Con este mismo tono, El Correo de la Tarde publicó los resultados de una encuesta "para escuchar la opinión de la calle" sobre el problema ferroviario. Por ejemplo, las preocupaciones de los comerciantes porteños tenían que ver con el perjuicio económico que significaba la caída de las ventas, "La solución, señor, no puede ser otra que la intervención del capital privado en los ferrocarriles", así se expresaba un comerciante de un negocio de comestibles

${ }^{23}$ Comisión Directiva de La Fraternidad, Comunicado de Prensa, año 1961, sin fecha certera.

${ }^{24}$ Editorial. "Llamamiento a la concordia", La Capital, Rosario, 30 de octubre de 1961. 
de la estación Constitución de la ciudad capital. ${ }^{25}$ El diario La Capital de la ciudad santafesina de Rosario publicaba “¿Cuánto cuesta una huelga?”, interrogante formulado por el Ministerio de Obras y Servicios Públicos a modo de propaganda antihuelga, junto a la imagen de un obrero ferroviario sentado en las vías vacías y acompañado de una respuesta contundente: "a los pasajeros pérdidas de tiempo y dinero, al trabajador un destino incierto, al país millones de pesos en pérdida" y además, sostenía la publicidad, "la huelga defendía el atraso y luchaba en contra del progreso y la racionalización necesaria para posibilitar la "vía rápida a la riqueza" ${ }^{26}$ Estas fuentes periodísticas enfatizaban los obstáculos que vivían los usuarios del transporte ferroviario de las ciudades para realizar sus actividades cotidianas y cuestionaban la medida de fuerza y responsabilizaban al colectivo de trabajadores del "problema ferroviario". No nos encontramos en estos medios con encuestas que tengan como protagonistas a las familias ferroviarias afectadas por las políticas del gobierno o informes que muestren la problemática de las localidades del interior del país frente a la situación económica.

En castigo a los manifestantes, la alta cuota de violencia registrada se acompañó con la creación de organismos de seguridad encargados de quebrar las acciones del movimiento, de vigilar los lugares adonde se podían generar episodios de enfrentamiento como seccionales gremiales y talleres ferroviarios que para el gobierno podían presentar mayores problemas. A nivel nacional, a partir del 29 de octubre de 1961 se establecieron medidas de seguridad a cargo de Gendarmería Nacional y de la Policía Federal consistentes en "vigilancia de las cabeceras y terminales ferroviarias [...] en puntos de partida de vehículos automotores [...] acuartelamiento de todo el personal de los cuerpos (montada, infantería y tránsito) y citación de 1000 oficiales que revistan en situación de retiro", con el objetivo de "reforzar la vigilancia de las zonas cubiertas". ${ }^{27}$ A partir del 1 de noviembre de 1961, las disposiciones gubernamentales declaraban la emergencia grave de la situación ferroviaria y

25 "El sueño de los durmientes", El Correo de la Tarde, 25 de octubre de 1961.

${ }^{26}$ La Capital, 4 de noviembre de 1961.

${ }^{27}$ El Litoral, 30 de octubre de 1961. También, La Prensa, subtitulaba: "Lugares que ocupa Gendarmería: efectivos de un total de 120 hombres custodian los talleres del Ferrocarril General San Martin, en Santos Lugares, provincia de Buenos Aires. Otros 60 gendarmes cumplen idéntica misión en los talleres Alberdi de Rosario, Provincia de Santa Fe [...]”, La Prensa, 29 de octubre de 1961. 
el establecimiento de la requisa del personal en Buenos Aires ${ }^{28}$ y a partir del 13 de noviembre en todo el país. ${ }^{29}$ Este procedimiento policial, que ponía a disposición del ejecutivo nacional al personal estatal ferroviario quien era notificado de su deber de concurrir a su lugar de trabajo, se acompañó, a partir del 5 de noviembre, con la creación de un Comando de Seguridad del Transporte encargado de asegurar el funcionamiento del servicio y la paz social.

Cuando a la lucha ferroviaria se sumaron los apoyos de la CGT (nos referimos a los paros generales en adhesión al ferroviario establecidos por este organismo), se incrementaron las medidas de prevención y vigilancia ante posibles "actos de violencia". Al respecto, Pontoriero (2015) sostiene que durante el gobierno de Frondizi la inclusión en el cuerpo jurídico argentino de la noción de un supuesto enemigo interno tenía como objetivo fundamental el de incorporar a las fuerzas armadas a la esfera de la seguridad interior. Estos organismos estaban impregnados del bagaje teórico que se elaboraba a nivel mundial con respecto al "peligro comunista". Con el propósito de afrontar la emergencia y de quebrar la medida de fuerza el "Comando de Seguridad del Transporte”, al mando del jefe de la policía federal, capitán de navío Recaredo Vázquez, tenía el objetivo de "asegurar los servicios de transporte y la tranquilidad pública [... porque] se tiene la certeza de que el comunismo aprovechará la huelga para producir atentados y actos de violencia". ${ }^{30} \mathrm{~A}$ partir del 6 de noviembre, El Litoral expresaba en sus títulos "Será reprimido todo intento de perturbación. Refuerzo de la Vigilancia”, lo que se manifestó en la vigencia del estado de sitio ordenado por el Ministerio del Interior hacia todos los gobiernos provinciales quienes no debían autorizar "acto público de ninguna naturaleza". ${ }^{31}$ Las características del nuevo organismo, junto con las disposiciones de extremar los mecanismos de control social, pueden sugerir que durante esta medida de fuerza (como así también a lo largo de otras llevadas a cabo por el movimiento obrero durante el gobierno de Frondizi), se inició un proceso de elaboración, prueba y perfeccionamiento de ciertos dis-

${ }^{28}$ Decreto Nacional del 9 de noviembre del 1961. Disponible en https://archive.org/ stream/Boletin_Oficial_Republica_Argentina_1ra_seccion_1961-11-09/1961-11-09\#mode/2up

${ }^{29}$ Consideramos que uno de los factores que incidió en ampliar la vigilancia fue el acontecimiento ocurrido el 11 de noviembre en Laguna Paiva que más adelante abordaremos.

${ }^{30}$ El Litoral, 11de noviembre de 1961.

${ }^{31}$ El Litoral, 6 de noviembre de 1961. 
positivos de control desarrollados por las fuerzas de seguridad que muestran el poder de las fuerzas armadas en la resolución de conflictos. ${ }^{32}$

\section{LAGUNA PAIVA SE DEFIENDE. MOVILIZACIÓN Y VIGILANCIA}

La coyuntura crítica de 1961 tensionó las estructuras sociales construidas en el espacio local,

un congreso zonal de fuerzas vivas de Laguna Paiva y zonas aledañas, representado por sociedades vecinales, comercio, industria y propietarios ha enviado una nota al presidente de la nación Dr. Arturo Frondizi [...] lo agobiante de la incertidumbre en nuestro dudoso futuro nos clama en solicitar a S.E. nos dé la certeza que los ramales que, pasando por Laguna Paiva, en comunicaciones con San Justo, San Cristóbal, San Javier, Balnearia, no serán alterados. Hemos de insistir en que esta zona lejos de permanecer estancada, se halla en continuo desarrollo y pleno florecimiento: eliminar el ferrocarril equivaldría seccionar una arteria vital a tan importante colonización. ${ }^{33}$

El Centro de Defensa Comercial paivense que impulsó esa reunión agregaba que "la supresión del tráfico sobre Laguna Paiva traería aparejada la desaparición inmediata de esta localidad [...] la desaparición total de Laguna Paiva!" ${ }^{34}$ Los salarios ferroviarios eran dinamizadores del consumo, las políticas del gobierno atentaban contra el mercado interno, la crisis laboral ferroviaria era el detonante de la crisis económica de la comunidad, por estas razones la huelga no fue un asunto de los obreros sino de toda la comunidad. El 27 de noviembre, la comisión ejecutiva de la seccional fraternal paivense hacía público su agradecimiento por la solidaridad demostrada tanto "moral como material" por el centro comercial local: "hacemos resaltar el proceder de muchos comerciantes que de una u otra forma han prestado su apoyo incon-

${ }^{32}$ Nos referimos al caso del Frigorífico Lisandro de la Torre, en el que se desplegaron estrategias de control social de nuevo tipo.

${ }_{33}$ El Litoral, 22 de octubre de 1961.

${ }^{34}$ El Litoral, 22 de octubre de 1961. 
dicional para que el gremio pueda seguir su justa lucha en esta hora decisiva para la clase obrera que el mismo pueblo argentino". ${ }^{35}$

Los maquinistas fraternales escapaban de la requisa del gobierno y los paivenses se escondieron cerca del arroyo Saladillo, zona de islas en la que pescaban y vivían con los víveres que sus compañeros les traían. Los gremios entregaban mercadería a los obreros y sus familias y los comerciantes, en solidaridad con la causa, no cerraban libretas. El marido de Mercedes durante el paro se encontraba en la localidad vecina de Naré, estaba escondido porque trabajaba en los depósitos del ferrocarril y el gobierno lo buscaba para que ponga en funcionamiento las máquinas. Ella se fue a vivir a la casa de su padre y recordaba que

Esos días hacíamos colas para dos panes, un kilo de papa, para un paquete de fideos. En el caso mío éramos 5 mujeres, 5 maridos. Mi papá, mis hermanos que eran ferroviarios. Teníamos que luchar si o si, mi papá al ver que se alargaba [la huelga] dijo: yo voy a cocinar para todos, pero tenemos que poner un poco cada uno. Poníamos lo que nos daban [...] Nos daban los que estaban en la Unión Ferroviaria. [...] Teníamos unos comerciantes que nunca cortaban la libreta, nos daban, el fideo, la harina, la grasa, el aceite, aunque no sabían qué iba a pasar. ${ }^{36}$

Aquellos hombres que no se escondían estaban en los locales gremiales (cuando estos no estaban clausurados), se ocupaban de confeccionar y repartir los boletines de huelga en los que por ejemplo se plasmaba periódicamente la "Lista de Carneros actualizada", compuesta de los nombres, apellidos, apodos y lugar de trabajo de aquellos considerados "traidores", los cuales eran criticados, atacados verbalmente y ridiculizados por la debilidad demostrada con el movimiento ferroviario. Eran duras las denominaciones a estos obreros y a sus familias, por ejemplo: "animales carneros ¿qué tal les va a ustedes?, por lo que nosotros apreciamos los vemos tranquilos y orgullosos de la traición que les hicieron a, los hasta ayer sus compañeros. [...] jVAYANSE! [...] Ustedes

\footnotetext{
${ }^{35}$ La Fraternidad, seccional Laguna Paiva. Pedido de publicación. "Nota al Señor Director", El Litoral, 27 de noviembre de 1961.

${ }^{36}$ Entrevista a la señora Mercedes Carnero por Luisina Agostini, septiembre de 2015, Laguna Paiva, Argentina.
} 
y sus hijos ya están marcados a fuego y nada ni nadie olvidará la traición y la mancha infligida a la clase obrera." ${ }^{7}$

Podemos ver qué la traición al movimiento ferroviario, que un obrero podía realizar, no era leída sólo como un problema dentro de la solidaridad y lealtad gremial, sino que era un problema social, una traición a la familia, entonces ferroviaria, y al pueblo en lucha.

Para la revista argentina de la nueva izquierda CHE del 14 de noviembre de 1961, "Laguna Paiva señala el camino". ${ }^{38}$ Los vagones quemados en la localidad paivense como resultado de la acción en defensa del paro ferroviario del 11 de noviembre de 1961 se ubicaban en la portada de la revista. La población paivense, en horas de la siesta pueblerina, impidió el paso de una locomotora que osaba transitar rompiendo la huelga; la máquina, conducida por un "krumiro" se aproximó por las vías y su silbato convocó a hombres, mujeres y niños quienes improvisaron acciones de detención de la formación. Mujeres del barrio obrero ${ }^{39}$ que estaba al costado de las vías levantaron durmientes para colocarlos sobre los rieles y detener el paso de la máquina, una manifestación se dirigió al kilómetro 40 y colaboró en la detención del vehículo generando tumultos y una balacera por parte de la policía que estaba custodiando la locomotora. Mercedes cuenta que

la villa obrera es una villa grande, parecía que dios las había hecho igordas y fornidas para eso! [...] Y con 10 mujeres alzábamos un durmiente [...] Cuando sentimos el pito de la máquina, la que salió y vio les gritaba a todas las vecinas, al barrio. Yo le avisaba a ella y ella a todas las que seguían... y todos salían [...]

${ }^{37}$ Boletín de Huelga, núm. 5 emitido por La Fraternidad y la Unión Ferroviaria seccionales de Laguna Paiva, sin fecha exacta.

${ }^{38}$ La revista CHE fue publicada entre 1960 y 1961 sus números se encuentran disponibles en http://americalee.cedinci.org/portfolio-items/che/. A propósito de esta revista la investigadora María Cristina Tortti (2017) estudió sobre sus orígenes y sus características, temas de interés así como también en las disputas en el interior del equipo de intelectuales que la integraron. No nos interesa aquí profundizar al respecto solo tener presente el origen de la revista que le otorgó protagonismo a Laguna Paiva en el número 27 del 17 de noviembre de 1961.

${ }_{39}$ El barrio de Villa Talleres fue el espacio donde se construyeron redes de sociabilidad que permitieron cierta organización pese al alto grado de espontaneidad de las acciones el 11 de noviembre de 1961. Este barrio, con servicios precarios para el año 1961, que se diferenciaba de los emplazamientos vecinales ubicados en el centro del pueblo que tenían un mejor desarrollo sanitario, se ubicaba al este del tendido del ramal Santa Fe- San Cristóbal. Se erigía el conjunto de viviendas habitadas por las familias de los obreros estables del taller. 
Pero, era una humareda de gente que corría a la par del tren tirándoles cascotes, con lo que encontraban le tiraban, pero la policía les tiraba tiros. ${ }^{40}$

Dos obreros ferroviarios resultaron heridos, la formación cayó a las vías y se produjo un incendio. El sindicalismo nacional se apropió de la gesta paivense como forma de simbolizar la lucha no sólo de los trabajadores ferroviarios sino de sus familias, la "familia ferroviaria" apareció como baluarte gremial y Laguna Paiva como "heroica". El Obrero Ferroviario, periódico de la Unión Ferroviaria, le otorgó sus páginas a los sucesos paivenses, reivindicó "la actitud de la mujer en nuestra lucha [...] y a las mujeres de Laguna Paiva que bajo su aparente debilidad femenina esconden la energía y el valor que a veces les falta a los hombres". ${ }^{41} \mathrm{El}$ sindicalismo ferroviario en un contexto de paro del "varón" (considerado el proveedor del hogar) sostenía que la irrupción de la mujer en el espacio público no implicaba un abandono del cumplimiento de su deber de esposa y madre (Agostini, 2018b).

Estas publicaciones nacionales sobre el acontecimiento local intentaron mostrar en la espectacularidad de las imágenes, las acciones del pueblo indignado, un pueblo ubicado en una geografía alejada de la capital del país y que entonces merecía reivindicarse, no por su lugar dentro del sistema ferroviario nacional, sino porque sus habitantes protagonizaron acciones violentas y eso los colocaba bajo la mirada nacional. Como explicamos en la introducción, no se trata de describir un acontecimiento vivido en un espacio local como mera respuesta a los procesos nacionales de manera que parezcan causa y efecto, sino de estudiar localmente los problemas derivados de las cuestiones relativas a las formas de construcción y percepción identitarias generadas por los actores en su dinámica social (Fernández, 2007, p. 37). ¿Por qué los habitantes de Laguna Paiva detuvieron e incendiaron el tren?, ¿por qué las mujeres levantaron durmientes?, ¿por qué y para qué Laguna Paiva luego del 11 de noviembre será duramente vigilada?, estas preguntas merecen formularse porque existe en la localidad una comunidad ferroviaria, que se identificó como tal cuando las bases materiales ferroviarias sobre las que los sujetos construyeron sus subjetividades, fueron puestas en cuestión, quisieron cerrarse y eliminarse. La historiadora Mirta Lobato (2001) plantea que

40 Entrevista a la señora Mercedes Carnero por Luisina Agostini, septiembre de 2015, Laguna Paiva, Argentina.

${ }^{41}$ El Obrero Ferroviario, Unión Ferroviaria, 20 de diciembre de 1961. 
"Las bases materiales (población, vivienda, instituciones) son sólo un aspecto del desarrollo de la comunidad: para poder definirla como tal es necesario analizar el proceso mediante el cual sus habitantes fueron dotando a esa comunidad de un significado" (p. 51). Esta observación es importante porque si bien no nos proponemos realizar aquí un trabajo exhaustivo en las maneras de recordar y de significar los procesos que tienen los sujetos paivenses, a continuación compartimos testimonios que creemos dan cuenta de los sentidos y significados de la comunidad paivense en defensa de su fuente laboral.

Walter, exobrero ferroviario de Paiva, consideró que el 3 de noviembre de 1961 comenzó el "proceso de organización del pueblo", existió una acción que tuvo como protagonistas no sólo a los trabajadores sino a todo el pueblo y puede encontrarse como antecedente de la jornada del 11 de noviembre,

los maquinistas se fueron todos al campo, a casa de parientes, se fueron del pueblo, quedaban los peones, y nosotros -los activistas que estábamos en la Unión Ferroviaria- [...] Hasta que un día entra un colectivo cargado de federales y se bajan en la esquina, sigue y para en la plaza, en la Unión Ferroviaria, cierran el local [...] Y, entonces, en el grupito que éramos, uno dice jhay que hacer una marcha!; otro dice jnecesitamos una bandera, hay que cantar el himno!, y había un hombre que dice yo voy a buscar la bandera al club de bochas "Chanta al Chico" y salió en bicicleta y apareció con la bandera de Argentina (risas). Entonces, habían salido del policlínico las enfermeras y habían venido con nosotros y entonces tomamos la bandera y salimos desde la esquina del paso nivel. A media cuadra estaba el colectivo, el colectivo había salido a allanar casas, buscaban a los comunistas, pero ya se habían rajado todos (risas) [...] las mujeres del policlínico todas atrás nuestro [...] se plegaba la familia. [...]) y nosotros con la bandera y adelante del colectivo los policías con carabinas, adelante del colectivo apuntando a la gente $[. ..] .^{42}$

${ }^{42}$ Entrevista al señor Walter Avellaneda por Luisina Agostini, septiembre de 2015, Laguna Paiva, Argentina. El diario El Litoral tituló el 4 de noviembre de 1961 al respecto de lo que recordó Walter que "En un procedimiento realizado en Laguna Paiva la policía federal procedió a detener 4 personas": la delegación local de la policía federal informó que durante esa jornada "por disposición del ejecutivo nacional, una comisión encabezada por el oficial subinspector Aldo Abel Alda procedió a la detención de Vito Regis Gomítolo a quien se le secuestró material de propaganda comunista". 
Para Walter, esta forma de organización -que lo tuvo como protagonista y que recuerda minuciosamente- fue particular porque no fue exclusivamente obra del sindicato. Se caracterizó por la adhesión de las mujeres del policlínico, personal de salud que era mayoritariamente femenino y que se aglutinó junto al grupo que se identificaba con el símbolo patrio que pertenecía al club barrial de bochas. La intolerancia a la requisa, al control policial, a las armas exhibidas contra los pobladores generó tensión a la comunidad.

Los policías locales cumplían órdenes de la policía federal que había tomado la responsabilidad de controlar al pueblo, se evidencia que existía persecución no sólo a los ferroviarios para que se presenten a trabajar, sino que el comunismo resonaba como un objetivo principal a controlar por las fuerzas de seguridad. El conflicto ferroviario puso a todos los habitantes de la localidad a prueba, obligó a que se definan las posiciones a tomar y, en el contexto de recrudecimiento de los aparatos represivos, los policías locales quedaron expuestos.

Los aviones militares pasaban al ras del pueblo, nos dijo Mercedes, ama de casa quien vivía en la Villa Obrera. Pirica, que era niña durante la huelga nos comentó: "viene la federal y en ese tiempo al lado de donde nosotros vivíamos vivía un hombre que era señalero, arreglaba señales y ahí iba el colectivito del ejército a buscarlos. Nosotros éramos chicos, estábamos en la vereda, ¡Tengo tan presente eso! Y veíamos como bajaban los soldados, te apuntaban, iban y lo sacaban de la casa porque había que arreglar señales." ${ }^{43}$

Esta situación de control social por parte de las fuerzas de seguridad se recrudeció luego del 11 de noviembre, el Comando de Seguridad del Transporte, en un comunicado que hacía referencia a los sucesos en Laguna Paiva, coincidió con la versión policial de los hechos al señalar que "este comando deja a criterio del trabajador argentino el calificar el modo de acción empleado en la emboscada, pero señala que actitudes de esta naturaleza han de merecer la más enérgica represión. En el caso de Laguna Paiva, se reforzarán los efectivos necesarios de la Policía Federal". ${ }^{4}$

43 Entrevista a las mujeres Dora Rojas y Pirica Rojas, realizada por Luisina Agostini, marzo de 2017, Laguna Paiva, Argentina.

${ }^{44}$ El Litoral, 12 de noviembre de 1961. El mismo diario publicó el 13 de noviembre de 1961: "Efectivos de la Policía Federal ocuparon hoy las instalaciones ferroviarias de Laguna Paiva [...] un nutrido contingente de la Policía Federal al mando del capitán Raúl Peyón, jefe de Coordinación Federal. Estas fuerzas, estimadas en aproximadamente 250 hombres se instalaron en la estación ferroviaria de Laguna Paiva, y en las primeras horas de hoy efectuaron procedimientos 
Los sucesos del 11 de noviembre en Paiva son los que resuenan en la prensa nacional, en los documentos gremiales como ejemplos de lo que el pueblo ferroviario era capaz de generar en un contexto de provocación. Cuando indagamos en las características del paro en el caso local podemos reconstruir momentos significantes para los protagonistas de la comunidad ferroviaria que explican aquel acontecimiento como parte de un proceso en el que conformaron diversas experiencias de lucha, algunas traumáticas que edificaron mientras su vida cotidiana se transformaba. De manera que los momentos del 11 de noviembre de 1961 no deben explicarse aislados del proceso previo en el que los sujetos se sintieron parte de la comunidad ferroviaria.

\section{LAS POSIBILIDADES DE LA HISTORIA LOCAL. REFLEXIONES FINALES}

La huelga que analizamos no se trató de una protesta por mejores salarios o condiciones de trabajo, sino que se realizó para impedir que el tren dejara de funcionar. Debido al recrudecimiento del conflicto y a las frustradas negociaciones entre las partes, el 1 de diciembre de 1961 el poder ejecutivo solicitó la mediación del cardenal Antonio Caggiano. Para el gremio, la actitud de negociación de las autoridades tenía que ver no sólo con el pedido de la Iglesia, sino con la crisis económica y social que vivieron las familias ferroviarias. También, con el malestar de toda la sociedad con las políticas del desarrollismo que retraían los salarios, la industria nacional y el bienestar general. ${ }^{45}$

El plan reivindicativo del movimiento ferroviario consistía en la constitución del directorio de la EFEA con representación obrera, la reapertura de talleres, el aumento de sueldos de acuerdo con la escala presentada oportunamente, la libertad de los detenidos y anulación de las sanciones aplicadas desde el inicio de la medida, nuevos estudios sobre la situación de los ramales clausurados, y el mantenimiento del régimen de indemnizaciones para el retiro voluntario de los empleos. Este plan fue presentado al cardenal Caggiano, para que lo entregue al gobierno que lo rechazó, el 3 de diciembre de 1961, por considerar que las peticiones obreras significaban "retrotraer la situación al

en las sedes de La Fraternidad y la Unión Ferroviaria, donde se llevó a cabo un requisamiento general y la detención del cuidador del local de esta última entidad, Sr. Juan Carlos Gau."

${ }^{45}$ La Fraternidad, Boletín de Huelga, 2 de diciembre de 1961. 
comienzo del conflicto sin sugerir ninguna medida constructiva o de concreta colaboración" ${ }^{46}$ Durante el tiempo que duró la negociación el gremio denunció que se continuaba con la requisa y la violencia hacia los ferroviarios.

Las negociaciones finalizaron el 10 de diciembre de 1961 cuando, sin abandonar las bases de la política de reestructuración gubernamental, se aceptaron las reivindicaciones obreras. Un aspecto significativo de este acuerdo fue la promesa por parte del directorio de EFEA de realizar un futuro estudio sobre la situación de cada una de las líneas y de los ramales clausurados. ${ }^{47}$

Nuestro trabajo se concentró en la huelga de 1961 pero es pertinente señalar que los problemas que estudiamos no fueron saldados al concluir la medida. Se registraron irregularidades en la normalización de los ramales, y en la reincorporación de obreros suspendidos, así como también en el pago de las indemnizaciones a los cesantes y en el cumplimiento del pago de los servicios de salud por parte del gobierno a los ferroviarios. Coincidimos con el investigador Ortega (2010), cuando plantea que la huelga no significó el triunfo del gobierno ni de los sindicatos, porque muchos obreros indemnizados no fueron reincorporados, el gobierno se debilitó políticamente, los ministros que eran considerados nefastos para el movimiento ferroviario renunciaron. Pero el paro contribuyó a que aumente entre la opinión pública el desprestigio sobre el ferrocarril como efectivo transporte. Es necesario no perder de vista estos problemas, que se profundizaron en años posteriores a 1961 e impactaron con brutalidad en las dinámicas socioeconómicas de pequeñas localidades de todo el país como lo señalamos en el apartado sobre el trabajo en los talleres de Laguna Paiva.

El repaso historiográfico que hemos realizado en este artículo nos permitió recuperar los estudios existentes sobre las políticas ferroviarias aplicadas en Argentina durante el siglo xx. La opción desarrollista se orientó a solucionar el problema del déficit del sistema aplicando medidas de racionalización que impactaron directamente sobre el trabajo y el trabajador ferroviario.

El recorrido por las características de los 42 días de huelga nos permitió explorar las prácticas discursivas de los sindicatos y autoridades de gobierno. La creciente militarización del conflicto y su impacto regional fueron analizados en Laguna Paiva. En este artículo recuperamos las experiencias de una

${ }^{46}$ El Litoral, 4 de diciembre de 1961.

${ }^{47}$ Decreto del Poder Ejecutivo, 10 de diciembre de 1961. En Comisión Directiva de La Fraternidad, Anexo núm. 2 del Comunicado de Prensa, 10 de diciembre de 1961. 
comunidad ferroviaria atravesada por los vaivenes económicos y políticos de la argentina posperonista.

La huelga en Paiva no fue un problema de los ferroviarios, sino de toda la comunidad. Eso nos permite entender, por un lado, que las políticas desarrollistas tensionaron las historias y experiencias que los habitantes de la comunidad ferroviaria construyeron alrededor de los talleres como referencia de sus identidades; por el otro, que el nivel de violencia y la forma de sostener el paro allí materializaron el giro autoritario de las decisiones del gobierno nacional y concretaron la injerencia de las fuerzas armadas en la resolución de los conflictos. Muchas veces parece difícil explicar las maneras en que postulados teóricos relacionados a doctrinas basadas en la seguridad se aplicaron efectivamente en Argentina en esos años; la huelga ferroviaria de 1961 es una oportunidad para atender a los procesos de militarización, prueba y perfeccionamiento de dispositivos de control social que comenzaron a ganar terreno sobre las resoluciones democráticas. Las detenciones a militantes sindicales, las formas de requisa, los allanamientos a los locales sindicales, la detención de militantes comunistas, la vigilancia demostrada con instalación de armas y hombres en Laguna Paiva son prácticas de esa preocupación por la seguridad frente al desarrollo.

El taller ferroviario en Paiva, como lugar de trabajo, permitió construir una sociabilidad política y de clase, también un colectivo social que incluyó familias y mujeres, quienes lideraron acciones de protesta que no pueden ser analizadas de la misma manera que en las grandes ciudades. El enfoque local nos permitió hacer más denso el estudio, complejizar la explicación sobre el "problema ferroviario". Porque lo que pasó en la localidad en 1961 encierra una particularidad, una singularidad y no se redujo a la jornada histórica y reconocida sindicalmente del 11 de noviembre de 1961, sino que lo que le otorgó sentido fue la comunidad ferroviaria manifestada. Las potencialidades del abordaje del conflicto desde la historia local en clave regional y desde la historia social nos permitieron complejizar la mirada sobre la construcción de las subjetividades y en este sentido contribuir al estudio de la existencia de una comunidad ferroviaria. 


\section{LISTA DE REFERENCIAS}

Agostini, L. (2018a). La comunidad ferroviaria de Laguna Paiva durante la huelga nacional de 1961. Sociabilidades, identidades y prácticas. (Tesis de maestría inédita). Universidad Nacional de Quilmes.

Agostini, L. (2018b). "Cuando las mujeres levantaron durmientes". Acciones disruptivas femeninas durante la huelga nacional ferroviaria de 1961 en Laguna Paiva (Santa Fe). Ponencia presentada en las V Jornadas ciNIG de Estudios de Género y Feminismos y III Congreso Internacional de Identidades, UNLP.

Agostini, L. y Brandolini, C. (2016). El ocaso de Laguna Paiva, "la ciudad del riel". Repercusiones y representaciones de los trabajadores ferroviarios sobre el cierre de los talleres. Páginas, 8(18), 97-119. Recuperado de http://revistapaginas.unr.edu. ar/index.php/RevPaginas

Bandieri, S. y Fernández, S. (eds.) (2017). La historia argentina en perspectiva local y regional. Nuevas miradas para viejos problemas. Buenos Aires, Argentina: Teseo.

Belini, C. y Korol, J. C. (2012). Historia económica de la Argentina en el siglo xx. Buenos Aires: Siglo XXI.

Censo Nacional de Población (1960). Censo Nacional de Población 1960, Tomo IV. Zona Central. Santa Fe-Córdoba: Dirección Nacional de Estadísticas y Censos. Recuperado de http://www.santafe.gov.ar/archivos/estadisticas/censos/Censo1960.pdf

Damín, N. y Aldao, J. (comps.) (2015). Sociología, historia y memoria de los pueblos ferroviarios. Buenos Aires: Publicaciones del Archivo Histórico de la Provincia de Buenos Aires.

Di Santo, A. (1999). La huelga ferroviaria de 1961. En E. Lucita, La patria en el riel. Un siglo de lucha de los trabajadores ferroviarios. Buenos Aires: Pensamiento Nacional.

Fernández, S. (comp.) (2007). Más allá del territorio. La historia regional y local como problema: Discusiones, balances y proyecciones. Rosario: Prohistoria.

Fernández, S. (2015). La perspectiva regional/local en la historiografía social argentina. Folia Histórica del Nordeste, 24, 189-202.

Filiberti, B. (2010). El desarrollismo argentino. Algunas ideas en torno a un pensamiento y una práctica. En J. Giani, 200 años construyendo la nación. Rosario: Paso de los Libres.

Gerchunoff, P. y Llach, L. (2005). El ciclo de la ilusión y el desencanto. Buenos Aires: Ariel.

Katz, J. y Kosacoff, B. (1989). El proceso de industrialización en Argentina: evolución, retroceso y prospectiva. Buenos Aires: CEAL. 
Larroca, J. y Vidal, A. (1987). Centenario de La Fraternidad. Rieles de lucha 1887-20 de junio-1987. Aporte para la historia del sindicalismo argentino. Buenos Aires: La Fraternidad.

López, M. (2007). Del equilibrio a la crisis de las empresas ferroviarias privadas.1917-1946. En M. J. López y J. Waddel, Nueva Historia del ferrocarril en la Argentina. 150 años de políticas ferroviarias. Buenos Aires: Lumiere.

López, M. J. y Waddel J. (2007). Nueva historia del ferrocarril en la Argentina. 150 años de políticas ferroviarias. Buenos Aires: Lumiere.

Lobato, M. (2001). La vida en las fábricas. Trabajo, protesta y política en una comunidad obrera, Berisso (1904-1970). Buenos Aires: Prometeo Libros-Entrepasados.

Mengascini, H. (2011). Huelgas y conflictos ferroviarios. Los trabajadores de Tandil en la segunda mitad del siglo xx. Buenos Aires: Prohistoria.

Müller, A. (2007). De trenes y pueblos "fantasma": acerca del impacto de la reducción del servicio ferroviario en la Argentina. Desarrollo Económico, 46(184), 597-612.

Ortega, F. (2010). De la modernización a la racionalización. Políticas adoptadas por Frondizi ante la crisis ferroviaria (1958-1962). H-industri@, 4(7). Recuperado de https://ojs.econ.uba.ar/index.php/H-ind/article/view/422

Paúl, O. (2015). Fundación y desarrollo de Laguna Paiva. Santa Fe: Imprenta Lux.

Pontoriero, E. (2015). Estado de excepción y contrainsurgencia: el Plan ConinTEs y la militarización de la seguridad interna en la Argentina (1958-1962). Contenciosa, 3(4).

Salerno, E. (2007). La evolución y los problemas de los Ferrocarriles del Estado durante la primera mitad del siglo xx. En M. J. López y J. Waddel, Nueva historia del ferrocarril en la Argentina. 150 años de políticas ferroviarias. Buenos Aires: Lumiere.

Scodeller, G. (2007). Conflictos sindicales durante los años del frondicismo en Mendoza. El caso de los trabajadores ferroviarios y del petróleo. Ponencia presentada en las XI Jornadas Interescuelas/Departamentos de Historia.

Schvarzer, J. (2000). La industria que supimos conseguir. Una historia político-social de la industria argentina. Buenos Aires: Ediciones Cooperativas.

Schvarzer, J. (1999) Los ferrocarriles de carga en la Argentina. Problemas y desafíos en vísperas del siglo XXI. Buenos Aires: CISEA, Centro de Investigación de la Situación del Estado Administrativo.

Sidicaro, R. (2002). Los tres peronismos. Buenos Aires: Siglo XXI.

Torre, J. C. (2001). Los años peronistas (1943-1955). Nueva Historia Argentina (T. 8). Buenos Aires: Editorial Sudamericana.

Tortti, M. C. (2017). Che y las tempranas redes de la nueva izquierda. AmÉRICALEE. Recuperado de www.americalee.cedinci.org 
Unzué, M. (2012). El Estado argentino (1976-2003). Ciclos de ajuste y cambios. Buenos Aires: Imago Mundi.

Vaccarezza, F. (2010). Políticas de desarrollo industrial en la Argentina (1940-2001) desde la sustitución a la apertura. (Tesis de maestría). Universidad Nacional de Tres de Febrero, Argentina.

Vicentin, E. (2013). La empresa automotriz IASFSA en Santa Fe. Características de una experiencia en los márgenes (1959-1969). Avances del Cesor, 10(10), 9-33.

Waddell, J. (2007). Los ferrocarriles británicos en la segunda mitad de la década de 1930 y la explotación de sus líneas. En J. Schvarzer, Estudios sobre la historia de ferrocarriles argentinos 1857-1940. Buenos Aires: Universidad de Buenos Aires.

\section{OTRAS FUENTES}

\section{Hemerografía}

Che, 1961, Buenos Aires, Argentina.

El Correo de la Tarde, 1961, Buenos Aires, Argentina.

El Litoral, 1961, Santa Fe, Argentina.

El Obrero Ferroviario, 1961, Buenos Aires, Argentina.

La Capital, 1961, Rosario, Argentina.

La Prensa, 1961, Buenos Aires, Argentina.

La Razón, 1961, Buenos Aires, Argentina. 